\title{
Study of flow characteristics and viscoelastic parameters of tumor cells in cancer growth
}

\author{
V.K. Katiyar \& K.S. Basavarajappa \\ Department of Mathematics \\ I.I.T Roorkee \\ Roorkee - 247667, India
}

\begin{abstract}
A mathematical model is presented which takes into account the most important events of diseased (Cancerous) cells associated with the mechanical behavior, and proliferation. Magnitude of the effector $E_{f}$ and complexes $E_{c}$ reflect the existence of cell deformation and locomotion. Generally the accumulation of cancerous cells which replicate in accordance with some law which is taken to be shear-induced form. Velocity of $0.055 \mathrm{~mm} / \mathrm{sec}$, proliferation range $0-200$ (numbers), decrease in viscosity $(<3.5 \mathrm{cp})$ are employed in numerical computations in reference to tumor cells. The resulting deformation rate is approximated to be $1.275 \mathrm{sec}^{-1}$. The binding of the diseased cell sets up from the location of the arrest. The stimulus of the blood shear environment induces the viscoelastic nature and the limitations of the diseased cell.
\end{abstract}

\section{Introduction}

Cancer is a group of many different diseases that generally affect cells the body's basic unit of life. Excess tissue can form a mass called a tumor which can be either benign or malignant proliferate uncontrollably. The cancer cells enter the blood stream and lymphatic system and are recognized as metastasis. Bone metastasis is common in breast cancer. Among the 
causative factors cigarette smoking is associated with lung cancer primarily noticed as Sarcoma. They generally rare account for all malignant neoplasms specially occur in uterine epithelial regions. As a whole, Sarcoma tumors are characterized by a very poor prognosis with a high rate of recurrent metastasis. Pathologically sarcomas in uterine appear into three main histologic subgroups as decreasing incidence: malignant mixed mullerian tumor (Carinosarcoma), Leiomyosarcoma and Endometrialstromal sarcoma.

Susan et al [8] presented the theoretical analysis of cancer crabs. Skalak [7] described the theoretical aspects of elastic energy in blood cell membrane. Sahay [6] studied the mechanical behavior of blood cells. AhShen [1] explained the diffusion equation for cancer cell with varying concentration. Chaplin et al [2] described the mathematical analysis of tumor stimulus of cancer cells. Simon et al [7] studied the mechanical properties of cells of porohyperelastic type. Melissa et al [4] analyzed the adhesion of breast cancer cells exposed to shear stresses. Ze-zhi will et al [10] compared the viscoelastic properties of carcinoma cells with perturbing agents. Marit et al [3] suggested the poor disease outcome of cell migration and growth in ovarian cancer. Patricia et al[5] analyzed the prognostic factors for soft tissue sarcomas.

In the present paper, an analysis has been carried out to study the mechanical behavior of cancer cell in relation to elastic parameters and histologic criteria assuming that the cancer cell migrates from one part of the body to other part of the body through blood vasculature.

\section{Formulation}

The tumor cells enter the blood stream and move back through the vessel to reestablish in the interstitial tissue. As a result, the tumor cells experience the deformation and stress when they pass through the membrane pores. The motility induced by the mechanical energy (elastic energy) and the shear rates at low and higher rates are the major characteristics of the tumor cell. For the biological cell as isotropic one, we take $\lambda_{1}$ and $\lambda_{2}$ as principal extensions in $\mathrm{x}_{1}$ and $\mathrm{x}_{2}$ directions respectively.

$\lambda_{1}=\frac{d y_{1}}{d x_{1}} \quad$ and $\quad \lambda_{2}=\frac{d y_{2}}{d x_{2}}$

Where $y_{1}$ and $y_{2}$ are final values. As the tumor cell diameter is higher than the membrane pore diameter, using Green's material strain tensor as,

$U_{j k}=1 / 2\left[D_{j} x_{i} D_{k} x_{i}-\delta_{j k}\right]$

We obtain 
$U_{j k}=1 / 2\left[\lambda_{i}^{2}-1\right]$

Where $\mathrm{D}_{\mathrm{j}} \mathrm{x}_{\mathrm{i}}=\mathrm{D}_{\mathrm{k}} \mathrm{x}_{\mathrm{j}}=\lambda i, \delta_{\mathrm{jk}}=1 \mathrm{j}=\mathrm{k}$ for homogenous isotropic material)

$$
T_{1}=h\left[\mu U_{11}+\lambda\left(U_{11}+U_{22}\right)\right] \text { And } T_{2}=h\left[\mu U_{22}+\lambda\left(U_{11}+U_{22}\right)\right]
$$

Where $h$ - thickness, $\mu$ and $\lambda$ are the material properties, $U_{11}$ and $U_{22}$ are the strain components.

$$
V=2 a P_{L}\left[1-\frac{K_{B}}{P_{L}}\left\{E_{b}+E_{c}\right\}\right]^{0.5 t}
$$

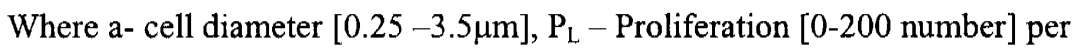
binding, $K_{B}-$ Bending moment $E_{f}$ (the effector composed of Chemical compounds mainly nucleic acid) binds the targeted cell and $E_{c}$ (the complexes includes transformed and diseased cell) to define the velocity of the Cancerous cell. Here 0.5 is chosen for initial setting. The living system is considered to be nonlinear, hence the dissipative system is far from the equilibrium, Boundary conditions are given by the cell proliferation for average time variation,

$\mid$ Vreal $\mid=V_{\text {min imum }}$

$\mathrm{E}_{\mathrm{f}} \rightarrow \infty($ rapid increase $)$ when $\Delta \mathrm{t}<0$

$\mathrm{E}_{\mathrm{c}} \rightarrow 0$ (diminsh), $\mathrm{E}_{\mathrm{f}} \rightarrow 0$ when $\Delta \mathrm{t}>0$

\section{Analysis}

Due to the locomotion the tumor cells are distined to shear induced deformation in the blood flow. The thickness of the tumor cell depends on the radius and the low and high shear. The varying radius under the locomotion can be modelled as,

$\mathrm{h}=\mathrm{H}(\mathrm{R})=\left[1-\left(\frac{r}{r_{0}}\right)^{2}\right]^{0.5}\left[C_{1}+C_{2}\left(\frac{r}{r_{0}}\right)^{2}+C_{3}\left(\frac{r}{r_{0}}\right)^{4}\right]$

$\mathrm{C}_{1}, \mathrm{C}_{2}$ and $\mathrm{C}_{3}$ are the cell material constants.

Expressing the velocity in terms of binding parameter $\mathrm{K}_{\mathrm{B}}$, equation now becomes 
$|V|=2 a P_{L}\left[1-\frac{\left(E_{f}+E_{c}\right)}{P_{I}} \frac{(0.083) E}{1-v^{2}}\left\{\left(1-\left(\frac{r}{r_{0}}\right)^{2}\right)^{0.5}\left\{C_{1}+C_{2}\left(\frac{r}{r_{0}}\right)^{2}+C_{3}\left(\frac{r}{r_{0}}\right)^{4}\right\}^{3}\right\}\right]^{0.5 t}$

E - Young's modules (dynes $/ \mathrm{cm}^{2}$ ), $v$ - Poisson's ratio $=0.5$ (restricted), Shear stress $\tau$ at the wall of the blood vasculature is,

as $\tau=(10.1845958) \mu \frac{\mathrm{Q}}{\mathrm{h}^{3}}$

Where $Q$ is the flow rate

$$
\begin{aligned}
& \mathrm{Q}=(12.568) \mathrm{aP}_{\mathrm{L}}\{ \\
& \left.\int_{r_{i n}}^{r}\left[1-\frac{\left(E_{f}+E_{c}\right)}{P_{L}} \frac{(0.083) E}{1-v^{2}}\left\{\left(1-\left(\frac{r}{r_{0}}\right)^{2}\right)^{0.5}\left\{C_{1}+C_{2}\left(\frac{r}{r_{0}}\right)^{2}+C_{3}\left(\frac{r}{r_{0}}\right)^{4}\right\}\right]^{3}\right]\right]^{0.5 t} \\
& d r\}
\end{aligned}
$$

The average time taken by tumor cell to penetrate through the membrane pore is,

$$
\mathrm{t}_{\mathrm{av}}=\mathrm{V}_{\mathrm{E}} / \mathrm{Q}
$$

Introducing Piola-Kirchoff stress tensor $S_{i j}$ to choose the elastic energy function comprised of strain components $e_{11}$ and $e_{22}$,

$$
S_{i j}=\frac{\partial w}{\partial e_{i j}}
$$

$w$ - elastic energy term, $e_{i j}$-strain components. For the tumor cell to penetrate through the membrane pores we choose the equation for w as Hart - Smith's function because it allows the description of biological cell membrane with material constants. For the tumor cell assumed to be incompressible isotropic such that, from (10) for $i=j=1$ and 2 we determine $S_{11}$ and $S_{22}$, further we obtain the resulting bending movements in $x_{1}$ and $x_{2}$ directions as, 


$$
\begin{array}{r}
\mathrm{M}_{\mathrm{B}}\left[x_{1}-\text { direction }\right]=\frac{(0.00394)}{\sqrt{2 e_{11}^{2}+1}} e_{11}-\frac{0.01985}{\sqrt{2 e_{11}+1}}\left[4 e_{11} e_{22}^{2}+\right. \\
\left.4 e_{11} e_{22}+2 e_{22}^{2}+e_{11}+2 e_{22}\right]
\end{array}
$$

$$
\begin{aligned}
& \mathrm{M}_{\mathrm{B}}\left[x_{2}-\text { direction }\right]=\frac{(0.00394)}{\sqrt{2 e_{11}^{2}+1}} e_{11}-\frac{0.01985}{\sqrt{2 e_{11}+1}}\left[4 e_{11}^{2} \mathrm{e}_{22}+\right. \\
& \left.4 e_{11} e_{22}+2 e_{11}^{2}+e_{11}+2 e_{22}\right]
\end{aligned}
$$

Where $e_{11}$ and $e_{22}$ are calculated using (3) for $i=1$ and 2 respectively.

\section{Results and Discussions}

Flow parameters and viscoelastic parameters have been discussed for the tumor cell. Mechanical stimulus of the shear stress, velocity and bending movements have been analyzed due to the induce of $\mathrm{E}_{\mathrm{f}}$ and $\mathrm{E}_{\mathrm{C}}$. The average velocity of the tumor cell is obtained as the increase of $4.631 \mathrm{~cm} / \mathrm{sec}$ (time range is5-540sec). Values of $E_{f}$ and $E_{C}$ are taken as $10 \mu \mathrm{g} / \mathrm{ml}$ and $4.5 \mu \mathrm{g} / \mathrm{ml}$. The radius of the tumor cell is $3.5 \mu \mathrm{m}$. the shear stress is $10 \mathrm{dynes} / \mathrm{cm}^{2}$, and the maximum shear stress is $17.5 \mathrm{dynes} / \mathrm{cm}^{2}$ when the tumor cell is arrested. The blood volume increases between the arrested region. The tumor cell exhibits the high motility than the normal cell. The bending movements are obtained as $0.265 \times 10^{9}$ dynes in $\mathrm{x}_{1}$-direction and $0.367 \times 10^{9}$ dynes in $\mathrm{x}_{2}$. direction. The quantification of the tumor cells with reference to sarcoma cells resembles the flow parameters of carcinoma cells. Results are in good agreement with those available in the literature.Figures (1) and (2) show the increase in $E_{f}$ value keeping $E_{C}$ unchanged, declines the velocity of the tumor cell, as a result the proliferation reduces. Further the increase in $E_{f}$ and $E_{c}$ results in high proliferation at the average diameter of the cancer cells. Figures (3) and (4) describe the values of stress between 0.125 and 1.35 dynes $/ \mathrm{cm}^{2}$ which are clustered together in the stretch ratio between 1.13 and 1.18 . The peak clustering depicts at 1.15 , here the significant increase in the motility ceases at 1.15 starts arrested at the vasculature by binding the targeted cell. The elastic energy of 1.175 dynes $/ \mathrm{cm}$ emerges as the critical elastic energy to induce the motility. 


\section{Conclusion}

Mechanical stimulus of effector and complexes with shear stress response shows the induce of variety of changes in the locomotion of the tumor cell with reference to sarcoma. The study shows the increase in the radius and velocity will influence the ability in the arrest of tumor cell and to bind with the vasculature wall. The binding of these cells has different metastatic capabilities.

\section{References}

[1] An-Shen Q1, Multiple solutions of a model describing cancerous growth, Bulletin of mathematical Biology, 50(1), pp.1-17, 1988.

[2] M.A.J. Chaplin, Susan M Giles, B.D., Sleeman, R.J. Jarvis, $A$ mathematical analysis of a model for tumor angiogenesis, $\mathbf{J}$. mathematical Biology, 33, pp.744-770, 1995

[3] Maarit A.Anttila, Raija H.Tammi, Markku I.Tammi Kari J.

Syrj ä annen, seppo V.Saarikoski,Veli-Matti Kosma, High levels of Stromal Hyaluronan Predict poor disease outcome in Epithelial Cancer, Cancer Research, 60, pp.150-155, 2000

[4] Melissa Summers Moss, Betty Sisken, Steve Zimmer, Kimberly W. Anderson, Adhesion of non metastatic and highly metastatic breast cancer cells to endothelial cells exposed to shear stress, Biorheology, 36, pp.359-371, 1999

[5] Patricia Pautier,Catherine Genestie,Annie Rey,Philippe Morice, Beatrice Roche, Catherine Lhomme, Christine Haie-Meder, Pierre Duvillard, Analysis of clinicopathologic prognostic factors for 157 uterine sarcomas and evaluation of a grading score validated for soft tissue sarcoma, Cancer, 88(6), pp.1425-14431, 2000

[6] K.B. Sahay, On the choice of strain energy function for mechanical characterisation of soft biological tissues, MEP Ltd, 13(1), pp.1114,1984

[7] B.R.Simon, M.V. Kaufmann, M.A. McAfee, A.L. Baldwin L.M. Wilson, Identification for Porohyperelastic analysis of large arteries, ASME, J. Bio. Mech. Engg, 120, pp.188-194. 1998

[8] R. Skalak, A. Tozeren, R.P. Zarda, S.Chien, Strain energy function of red blood cell membrranes, Biophysical Journel, 13, pp.245265,1973

[9] Susan. G. Langreth, Spermiogenesis in Cancer Crabs, J. Cell Biology, 43, 44, pp.575-603, 1970

[10] Ze-Zhi Wu, Gang Zhang, Mian long,, Hong-Bin Wang Guan-Bin Song and Shao-Xi Cai, Comparison of the Viscoelastic Properties of normal hepatocytes and hepatocellular carcinoma cells under cytoskeletal perturbation, Biorheology, 37, pp.279-290, 2000 


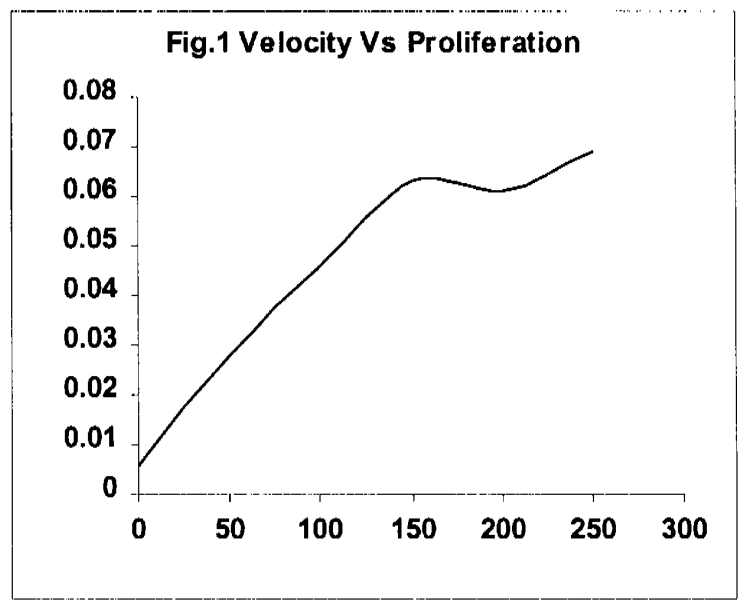

x-axis: Proliferation $\left(\mathrm{P}_{\mathrm{L}}\right.$ in numbers $)$ y-axis: Velocity $(\mathrm{mm} / \mathrm{sec})$

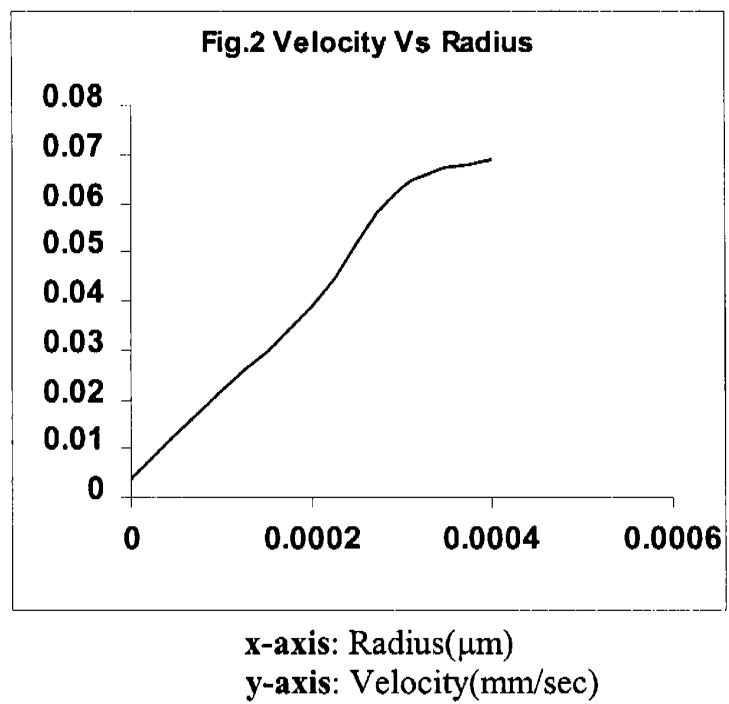


408 Simulations in Biomedicine $V$

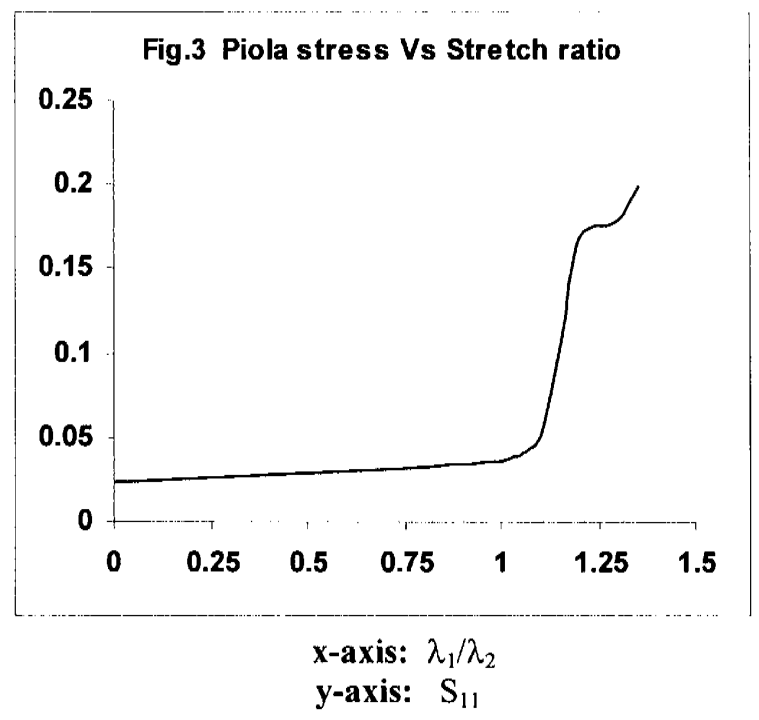

Fig.4 Piola stress Vs Stretch ratio

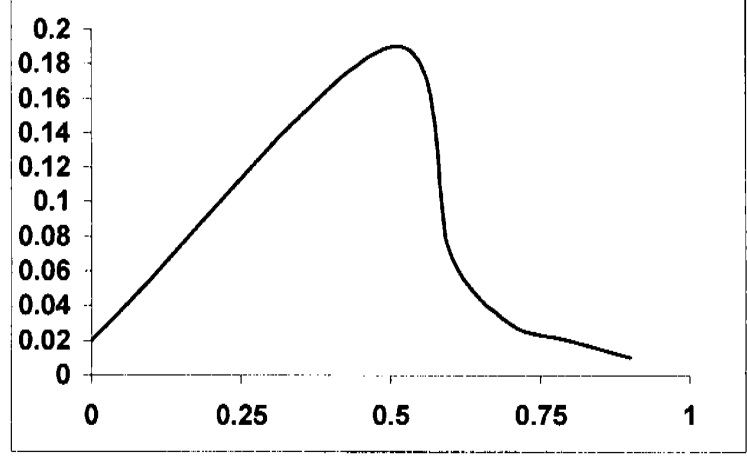

x-axis: $\lambda_{2} / \lambda_{1}$

y-axis: $S_{22}$ 